\title{
Emotional Intelligence and Its Relationship With General Health Among the Students of University of Guilan, Iran
}

\author{
Hassan Farrahi, ${ }^{1}$ Seyed Mousa Kafi, ${ }^{2}$ Tamjid Karimi, ${ }^{3, *}$ and Robabeh Delazar ${ }^{2}$ \\ ${ }_{1}^{1}$ Department of Psychiatry, School of Medicine, Guilan University of Medical Sciences, Rasht, IR Iran \\ ${ }^{2}$ Department of Psychology, School of Humanities, University of Guilan, Rasht, IR Iran \\ 3 Department of Psychology, Shafa Hospital, Guilan University of Medical Sciences, Rasht, IR Iran \\ *Corresponding author: Tamjid Karimi, Department of Psychology, Shafa Hospital, Guilan University of Medical Sciences, Rasht, IR Iran. Tel: +98-9117613572, Fax: +98-1316666268, \\ E-mail: tamjid.karimi@gmail.com
}

Received: April 24, 2014; Revised: February 22, 2015; Accepted: March 15, 2015

\begin{abstract}
Background: Particularly, this concept has used for examination of its empact on health of various people groups. Given the importance of students' health, this study investigated the relationship between emotional intelligence and general health.

Objectives: The concept of emotional intelligence has attracted growing interest from researchers working in various fields. This study investigated the relationship between emotional intelligence and general health.

Materials and Methods: In this cross-sectional study, 136 students were selected from the University of Guilan, north of Iran, using simple random sampling. The subjects completed the Schutte self-report emotional intelligence test and general health questionnaire.

Results: The results showed a significant correlation between emotional intelligence and general health. Also, results indicated that emotional perception and emotional utilization are predictors of general health.

Conclusions: The findings reflect that emotional intelligence can play an important role in general health.
\end{abstract}

Keywords: Emotional Intelligence; Mental Health; Student

\section{Background}

Emotional intelligence has received much attention in the literature (1-4). According to Perez et al. (5) the general concept of emotional intelligence is partly rooted in Thorndike's (6) theory of "social intelligence" and Gardner's (7) theory on multiple intelligences.

Research on emotional intelligence began primarily in the early 1990's (8). The topic of emotional intelligence has appeared in Goleman's (9) "best-selling" book. According to Goleman, being able to monitor and regulate one's own feelings, understand the feeling of others and use that "emotion" or "feeling" knowledge to guide thoughts and actions is known as emotional intelligence. The theory of emotional intelligence proposed by Salovey and Mayer (8) provides a new framework to investigate social and emotional adaptation. Emotional skills can be developed through learning and experience and posit four central abilities: perceiving, using, understanding, and managing emotions.

There has been an increasing interest regarding the association between emotional intelligence and general and mental health (1). Higher emotional intelligence has been found to be correlated to lower psychological distress (10), moderately related to lower depression $(11,12)$ and strongly to lower anxiety (12). Similarly, high emotional intelligence has been moderately related to lower levels of negative affect or depression (2), mildly related to lower levels of anger, sadness, fear, jealousy, and sham,
(13) and strongly related to lower general health $(14,15)$. As a result, individuals with high emotional intelligence possibly are being more able to resist general and mental health problems.

In Iran, there is increasing acceptance of emotional intelligence concept and its application in educational practice. Fata et al. (16) found that emotional intelligence is a significant predictor of general mental health and emotional intelligence enhancement.

Especially, adaptability skills lead to increased mental health Banihashemian and Moazzen (17) found a positive relationship between general health and emotional intelligence. Shhadi et al. (18) also, concluded that emotional intelligence is reversely related to symptoms of anxiety and is capable of predicting anxiety symptoms.

The results of some researches have suggested that ethnic, geographic, cultural, and other demographic factors may play an important role in both emotional intelligences and mental or general health $(4,6,10,14,16)$.

Thus, it is necessary that above-mentioned variables in age, gender, cultural, ethnic, regional, and other groups are studied separately. Considering this point, the purpose of this study was to assess the relationship between emotional intelligence and mental health among students in the University of Guilan, north of Iran, which may have differences in comparison with other populations.

Copyright (C) 2015, Mazandaran University of Medical Sciences. This is an open-access article distributed under the terms of the Creative Commons Attribution-NonCommercial 4.0 International License (http://creativecommons.org/licenses/by-nc/4.0/) which permits copy and redistribute the material just in noncommercial usages, provided the original work is properly cited. 
Farrahi Het al.

\section{Materials and Methods}

This cross-sectional study was performed on all undergraduate students of Guilan University during 2010 - 2011. The samples included 62 men and 74 women. The subjects' age range was from 19 to 24 (mean \pm standard deviation $=21.40 \pm 2.70$ ). They were selected according to the stratified random sampling method.

To collect data, Schutte self-report emotional intelligence test (SSEIT) and general health questionnaire (GHQ-28) were used.

Schutte self-report emotional intelligence test comprises 33 self-report statements designed to measure the components of emotional intelligence proposed in Salovey and Meyer's original theory of emotional intelligence (8). Participants were asked to rate on a Likert scale the extent to which they strongly disagreed (1) or strongly agreed (5) with each statement such as "I have control over my emotions" or "I expect good thing to happen." The instrument measures emotional management (in self and others), emotional perception and emotional utilization (19). The SSEIT has an acceptable level of internal consistency ( $\alpha$ $=0.87)$ and test-retest reliability $(r=0.78)(20)$. Furthermore, Williams et al. (21) reported good internal reliability $(\alpha=0.86)$. The test-retest reliability and Cronbach's $\alpha$ of the Persian version of SSREI was 0.77 and 0.85 , respectively $(\mathrm{P}<0.001)$. The correlation coefficient of emotional intelligence scale with "the satisfaction with life scale," "depression anxiety stress scales" and "trait meta-mood scale" were also found to be $0.48,-0.46$ and 0.49 respectively, which were also significant $(\mathrm{P}<0.001)(22)$.

Moreover, GHQ-28 is a 28 -items measure that has been widely used since 1978 after being introduced by Goldberg and Williams (23). This questionnaire asks respondents to indicate how their health has been over the last few weeks on 4-point scales (better than usual $=0$, much worse than usual =3). The GHQ-28 has four scales: somatization, social dysfunction, anxiety and depression. Higher scores indicate more self-reported psychological symp- toms (15). Cronbach's alpha coefficients for somatization, anxiety, social dysfunction and depression were $0.67,0.71$, 0.59 , and 0.75 , respectively (24). In Iran, reliability and validity of GHQ-28 have studied in some investigations. In one of these researches in Isfahan, Iran, criterion validity, Chronbach's alpha and split reliability coefficient were found to be $0.78,0.97$, and 0.90 , respectively (25).

\section{Results}

In the present study, 136 subjects participated and completed the questionnaires. From this group, 74 cases were female and 62 were male. The result of t-test showed that there was no significant statistical difference in age between two subgroups (male and female).

The mean and standard deviation of all subjects in SSEIT were 21.40 and 2.70 , respectively. The mean and standard deviation of GHQ were 14.12 and 6.78, respectively.

The results showed a correlation between emotional intelligence and general health scales. The correlation between emotional intelligence and sum of general health was -0.36. Similarly, the correlations between emotional intelligence and somatization, anxiety, social dysfunction, and depression scales were $0.24,-0.25,-0.37$, and -0.27 , respectively.

Table 1 shows correlations between scales of general health and subscales of emotional intelligence.

According to the Table 1, emotional management is not correlated with scales of general health. In contrast, emotional perception is mildly, and emotional utilization is moderately correlated with scales of general health.

To determine whether the emotional intelligence scales significantly predicted variance of general health, multiple regression analysis was conducted (Table 2).

Multiple regression results showed emotional management is not correlated with scales of general health. In contrast, emotional perception is mildly, and emotional utilization is moderately correlated with scales of general health.

Table 1. Correlations Between Subscales of General Health and Scales of Emotional Intelligence

\begin{tabular}{lccccc}
\hline Variables & Somatization & Anxiety & Social Dysfunction & Depression & Total GHQ $^{\mathrm{a}}$ \\
\hline Emotional management & -0.14 & 0.11 & -0.14 & 0.12 & 0.11 \\
Emotional perception & $-0.18^{\mathrm{b}}$ & $0.22^{\mathrm{b}}$ & $-0.32^{\mathrm{b}}$ & $0.18^{\mathrm{b}}$ & $0.29^{\mathrm{b}}$ \\
Emotional utilization & $-0.27^{\mathrm{C}}$ & $0.35^{\mathrm{C}}$ & $-0.51^{\mathrm{c}}$ & $0.58^{\mathrm{C}}$ & $0.54^{\mathrm{C}}$ \\
\hline
\end{tabular}

a General health questionnaire.

b $\mathrm{P}<0.050$.

c $\mathrm{P}<0.010$.

Table 2. Predictors of General Health

\begin{tabular}{lccc}
\hline Variables & $\mathbf{b}$ & $\boldsymbol{\beta}$ & $\mathbf{t}$ \\
\hline Emotional management & -0.21 & -0.17 & $1.84^{\mathrm{a}}$ \\
Emotional perception & -0.36 & -0.19 & $2.48^{\mathrm{a}}$ \\
Emotional utilization & -0.42 & -0.31 & $3.39^{\mathrm{a}}$ \\
\hline
\end{tabular}

a $\mathrm{P}<0.050$ 
Farrahi Het al.

\section{Discussion}

This study examined the relationship between three emotional competencies (management, perception, and utilization) and four scales of general health (somatization, anxiety, social dysfunction and depression) among the Guilan University students. The current study also examined whether emotional intelligence can predict general health.

The results of this study were similar to those of previous students. For example, a meta-analysis of 44 effect sizes based on the response of 7898 participants found that higher emotional intelligence was significantly associated with better health (14).

The adaptive perception of emotion, use of emotion to enhance cognition, understanding of emotion and regulation of emotion may contribute to mental and physical health in various ways. Matthews et al. pointed out that level of emotional intelligence may have implications for both mental disorders in which emotion plays a central role as well as disorders that relate to non-emotional features of emotional intelligence. Mood and anxiety disorders are examples of disorders that have maladaptive emotional state of core symptoms (26). The better perception, understanding and management of emotion of those with higher emotional intelligence may prevent the development of maladaptive emotional states associated with mood and anxiety disorders. Research has shown those with higher emotional intelligence tend to have more positive mood typically and are better able to repair the mood after a negative mood induction (27).

In another study, individuals with high levels of emotional intelligence have several advantages over individuals with low emotional intelligence levels. These advantages include emotional self-awareness, stress management, problem-solving, mood regulation, empathy and the ability to prevent distress from swamping one's ability to think clearly. These qualities are highly desirable and important for successful living in the world (28).

The evidence suggests that the emotional perception and emotional utilization are predictors of general health. This result corresponds to the findings of many studies $(1,11,16-18)$. The ability to regulate emotions is one of the higher more psychologically integrated processes and concerns whether the individual is trying to improve a bad mood, dampen a good mood, or leave the mood alone (28). Some of these abilities may serve as buffers to physical illness. Further, those with higher emotional intelligence might be better able to follow through on commitments to health behavior and show better medical compliance (14). In summary, the results of this study revealed that emotional intelligence can serve as a protective and supportive function for general health and its components.

The current study has some limitations. First, the collection of data in this study relied on university students, self-report. This may have produced socially desirable responses. Second, the current study did not control the effect of any other potential predictors (e.g. personality variables) of general health. Future research should aim to clarify this issue. Third, because of the small sample of this research, the current results may not be generalized to other students. Future research in this area with larger sample sizes and a wider battery of measures is needed in order to substantiate the contribution of emotional intelligence to general health. Finally, the design of this study is cross-sectional and cannot establish a causal relationship. We hope the results of this study provide a basis for the studies aimed to determine the causal relationship between emotional intelligence and general health in Iranian university students.

\section{Acknowledgements}

The present article was based on a research performed in the University of Guilan. We would like to thank Motamed for his unassuming cooperation in facilitating the performance of this research project.

\section{Authors' Contributions}

Hassan Farrahi conceived and designed the research, collected and analyzed the data, and drafted the manuscript. Seyed Mousa Kafi participated in performing the statistical analysis, designing the evaluation, and gathering and evaluating the data. Tamjid Karimi participated in gathering and analyzing the data, literature review, and writing the manuscript. Robabeh Delazar participated in sampling, administrating the tests, analyzing the data, and writing the manuscript. All authors read and approved the final manuscript.

\section{Declaration of Interest}

Non declared.

\section{References}

1. Williams C, Daley D, Burnside E, Hammond-Rowley S. Can trait Emotional Intelligence and objective measures of emotional ability predict psychopathology across the transition to secondary school? Pers Individ Dif. 2010;48(2):161-5.

2. Uva M, Timary P, Cortesi M, Mikolajczak M, Blicquy P, Luminet O. Moderating effect of emotional intelligence on the role of negative affect in the motivation to drink in alcohol-dependent subjects undergoing protracted withdrawal. Pers Individ Dif. 2010;48(1):16-21.

3. Costarelli V, Stamou D. Emotional Intelligence, Body Image and Disordered Eating Attitudes in Combat Sport Athletes. J Exerc Sci Fit. 2009;7(2):104-11.

4. Kluemper DH. Trait emotional intelligence: The impact of core-self evaluations and social desirability. Pers Individ Dif. 2008;44(6):1402-12.

5. Perez JC, Petrides K,, Furnham A. Measuring trait emotional intelligence. In: Schulze R, Roberts RD, editors. Emotional intelligence: An international handbook. Boston, MA: Hogrefe \& Huber; 2005.

6. Thorndike EL. Intelligence and its uses. Harper's Mag. 1920;140:227-35.

7. Gardner H.Frames ofmind:The theory ofmultiple intelligences. New York, NY: Basic Books; 1985.

8. Mayer JD, Salovey P. Emotional Intelligence. Imag, Cogn Pers. 1989;9(3):185-211. 
9. Goleman D. Emotional Intelligence: Why It Can Matter More Than IQ.New York, NY: Bantam Books; 1995.

10. Austin EJ, Saklofske DH, Egan V. Personality, well-being and health correlates of trait emotional intelligence. Pers Individ Dif. 2005;38(3):547-58.

11. Goldenberg I, Matheson K, Mantler J. The assessment of emotional intelligence: a comparison of performance-based and selfreport methodologies. J Pers Assess. 2006;86(1):33-45.

12. Mikolajczak M, Luminet O, Leroy C, Roy E. Psychometric prop erties of the Trait Emotional Intelligence Questionnaire: factor structure, reliability, construct, and incremental validity in a French-speaking population. J Pers Assess. 2007;88(3):338-53.

13. Mikolajczak M, Nelis D, Hansenne M, Quoidbach J. If you can regulate sadness, you can probably regulate shame: Associations between trait emotional intelligence, emotion regulation and coping efficiency across discrete emotions. Pers Individ Dif 2008;44(6):1356-68.

14. Schutte NS, Malouff JM, Thorsteinsson EB, Bhullar N, Rooke SE. A meta-analytic investigation of the relationship between emotional intelligence and health. Pers Individ Dif. 2007;42(6):921-33.

15. Greven C, Chamorro-Premuzic T, Arteche A, Furnham A. A hierarchical integration of dispositional determinants of general health in students: The Big Five, trait Emotional Intelligence and Humour Styles. Pers Individ Dif. 2008;44(7):1562-73.

16. Fata L, Mootabi F, Shakiba S, Barooti E. Social-Emotional intelligence as predictor of general mental health. Quart J Psychol Stud. 2008;4(2):101-24.

17. Banihashemian K, Moazzen M. Relation between head masters' general health and emotional intelligence and job satisfaction of teachers. J of Behavioral Sci. 2010;4(1):45-50.

18. Shhadi A, Soltani Shurbakhorloo E, Hashemi Razini S. On the re- lationship between emotional intelligence and its components with symptoms of anxiety [in persian]. J Fundam Ment Health 2011;12(4):652-61.

19. Petrides KV, Furnham A. On the dimensional structure of emotional intelligence. Pers Individ Dif. 2000;29(2):313-20.

20. Schutte NS, Malouff JM, Hall LE, Haggerty DJ, Cooper JT, Golden CJ, et al. Development and validation of a measure of emotiona intelligence. Pers Individ Dif. 1998;25(2):167-77.

21. Williams C, Daley D, Burnside E, Hammond-Rowley S. Measuring Emotional Intelligence in preadolescence. Pers Individ Dif. 2009;47(4):316-20.

22. Bayani AA. Reliability and validity of the persian version of the emotional intelligence scale among uneversity students [in persian].J Fundam Ment Health. 2009;11(3):202-12.

23. Goldberg D, Williams P. A user's guide to the General Health Questionnaire.Windsor, UK: NFER-Nelson; 1988.

24. Cheung P, Spears G. Reliability and validity of the Cambodian version of the 28-item General Health Questionnaire. Soc Psychiatry Psychiatr Epidemiol. 1994;29(2):95-9.

25. Ebrahimi A, Molavi H, Moosavi G, Bornamanesh A, Yaghobi M. [Psychometric properties and factor structure of General Health Questionnaire 28 (GHQ-28) in Iranian psychiatric patients]. J Res Med Sci. 2007;5(1):5-12.

26. Matthews G, Zeidner M, Roberts RD. Emotional intelligence: Science and myth. Cambridge, MA: MIT Press; 2002.

27. Schutte NS, Malouff JM, Simunek M, McKenley J, Hollander S Characteristic emotional intelligence and emotional well-being. Cogn Emot. 2010;16(6):769-85.

28. Spence G, Oades LG, Caputi P. Trait emotional intelligence and goal self-integration: important predictors of emotional wellbeing? Pers Individ Dif. 2004;37(3):449-61. 